M. Matzapetakis • M. Dakanali • C.P. Raptopoulou V. Tangoulis $\cdot$ A. Terzis $\cdot$ N. Moon $\cdot$ J. Giapintzakis A. Salifoglou

\title{
Synthesis, spectroscopic, and structural characterization of the first aqueous cobalt(II)-citrate complex: toward a potentially bioavailable form of cobalt in biologically relevant fluids
}

Received: 5 February 2000 / Accepted: 14 April 2000

\begin{abstract}
Citric acid represents a class of carboxylic acids present in biological fluids and playing key roles in biochemical processes in bacteria and humans. Its ability to promote diverse coordination chemistries in aqueous media, in the presence of metal ions known to act as trace elements in human metabolism, earmarks its involvement in a number of physiological functions. Cobalt is known to be a central element of metabolically important biomolecules, such as $\mathrm{B}_{12}$, and therefore its biospeciation in biological fluids constitutes a theme worthy of chemical and biological perusal. In an effort to unravel the aqueous chemistry of cobalt in the presence of a physiologically relevant ligand, citrate, the first aqueous, soluble, mononuclear complex has been synthesized and isolated from reaction mixtures containing $\mathrm{Co}(\mathrm{II})$ and citrate in a $1: 2$ molar ratio at $\mathrm{pH} \sim 8$. The crystalline compound $\left(\mathrm{NH}_{4}\right)_{4}\left[\mathrm{Co}\left(\mathrm{C}_{6} \mathrm{H}_{5} \mathrm{O}_{7}\right)_{2}\right](\mathbf{1})$ has been characterized spectroscopically (UV/vis, EPR) and crystallographically.
\end{abstract}

Supplementary material. Tables S1-S5 and Fig. S1, containing tables of X-ray crystal structure positions, thermal parameters, detailed bond lengths and angles, structure factors, and a packing diagram for $\left(\mathrm{NH}_{4}\right)_{4}\left[\mathrm{Co}\left(\mathrm{C}_{6} \mathrm{H}_{5} \mathrm{O}_{7}\right)_{2}\right]$, are available in electronic form on Springer Verlag's server at http://link.springer.de/journals/jbic/

M. Matzapetakis · M. Dakanali · A. Salifoglou ( Department of Chemistry, University of Crete, Heraklion 71409, Greece

e-mail: salif@chemistry.uch.gr

Tel.: +30-81-393652

Fax: $+30-81-393601$

C.P. Raptopoulou $\cdot$ V. Tangoulis $\cdot$ A. Terzis

Institute of Materials Science, NRCPS "Demokritos",

Aghia Paraskevi 15310, Attiki, Greece

J. Giapintzakis

Institute of Electronic Structure and Laser, FO.R.T.H.,

71110 Heraklion, Greece

N. Moon

Biophysics Research Division, University of Michigan,

Ann Arbor, MI 48109, USA
Its X-ray structure consists of a distorted octahedral anion with two citrate ligands fulfilling the coordination requirements of the $\mathrm{Co}(\mathrm{II})$ ion. The magnetic susceptibility measurements of $\mathbf{1}$ in the range from 6 to $295 \mathrm{~K}$ are consistent with a high-spin complex containing $\mathrm{Co}(\mathrm{II})$ with a ground state $S=3 / 2$. Corroborating this result is the EPR spectrum of $\mathbf{1}$, which shows a signal consistent with the presence of a $\mathrm{Co}$ (II) system. The spectroscopic and structural properties of the complex signify its potential biological relevance and participation in speciation patterns arising under conditions consistent with those employed for its synthesis and isolation.

Key words Cobalt-citrate complex $\cdot$ Speciation · Structure $\cdot$ Electron paramagnetic resonance Bioavailability

\section{Introduction}

Organic acids have been known to play an essential role in physiological processes [1]. Outstanding among them are multi-carboxylic acids, the involvement of which earmarks a number of biochemical processes. Citric acid, a tricarboxylic acid [2], is considered as a pivotal organic acid, participating in key metabolic functions such as those governed by the tricarboxylic acid cycle, the Krebs cycle [3, 4]. Its composition of three carboxylate and one hydroxyl groups bestows upon it unique chemical properties that render it essential in biological media. Its metal ion chelating ability, exemplified in a multitude of coordination modes, is but one such property prominently emerging from its participation in a number of enzymic systems. As a substrate, citric acid is bound to the active site iron-sulfur cluster in aconitase [5-7] and as an essential ligand it participates in the primary coordination sphere of molybdenum found in nif $\mathrm{V}^{-}$nitrogenase [8]. Citric acid's metal ion chelating abilities bring about changes in the solubility of metals and influence sig- 
nificantly their mobilization and bioavailability in biological media. Among the metals circulating in human plasma and bearing biologically essential functions is cobalt. Cobalt has been firmly established to exist in the human body as the metal cofactor of the $\mathrm{B}_{12}$ coenzyme and vitamin $\mathrm{B}_{12}$ molecules [9-12]. Albeit a trace element, its significance in the functional biochemistry of the above molecules stands high, with an absence or declining levels of the latter in the human body resulting in pathophysiological conditions leading to anemic symptoms [13]. Alternatively, excessive amounts of cobalt in humans from habitual or professional exposure have been known to result in toxic effects, manifested in heart disease and excess formation of red corpuscles $[14,15]$. In all of the aforementioned examples, several aspects of cobalt chemistry, starting from its original form available in plasma, have not been elucidated. The interaction of cobalt with tricarboxylic acids such as citrate provides a scaffold onto which reasonable hypotheses can be built pertaining to that metal ion's chemical speciation in biological fluids. The presence of citric acid in human plasma in submillimolar concentration is certainly a pivotal factor that might influence cobalt's speciation and bioavailability, directing pertinent chemistries relevant to biological molecules. Thus far, however, scant information has been available on cobalt tricarboxylate chemistry, with equally unavailable structural data on elusive complexed forms of high solubility in biological media. The lack of such data prompted us to investigate the cobalt-citrate chemistry, targeting low molecular weight complexes soluble in aqueous media. Herein, we report on the synthesis, isolation, spectroscopic, and structural characterization of a novel cobalt-citrate complex from aqueous solutions.

\section{Materials and methods}

All manipulations were carried out in the open air. $\mathrm{Co}\left(\mathrm{NO}_{3}\right)_{2} \cdot 6 \mathrm{H}_{2} \mathrm{O}$ and citric acid monohydrate were purchased from Fluka. Ammonia and ethanol were purchased from Riedelde Haën. Nano-pure quality water was used for all reactions.

Preparation of $\left(\mathrm{NH}_{4}\right)_{4}\left[\mathrm{Co}\left(\mathrm{C}_{6} \mathrm{H}_{5} \mathrm{O}_{7}\right)_{2}\right](\mathbf{1})$

$\mathrm{Co}\left(\mathrm{NO}_{3}\right)_{2} \cdot 6 \mathrm{H}_{2} \mathrm{O}(0.15 \mathrm{~g}, 0.51 \mathrm{mmol})$ was dissolved in nano-pure water. To that solution, citric acid monohydrate $(0.22 \mathrm{~g}$, $1.04 \mathrm{mmol}$ ) was added under continuous stirring. The resulting reaction mixture was stirred overnight at $50^{\circ} \mathrm{C}$. Next day the solution was taken to dryness with a rotary evaporator. The solid was re-dissolved in water and the $\mathrm{pH}$ was raised to $\sim 8$ with aqueous ammonia. Ethanol was subsequently added and the solution was placed in the refrigerator $\left(4^{\circ} \mathrm{C}\right)$. Several days later, pink crystals appeared which were isolated by filtration. Yield: $0.15 \mathrm{~g}(57.1 \%)$. Analysis: calc. for $\mathrm{C}_{12} \mathrm{H}_{26} \mathrm{O}_{14} \mathrm{~N}_{4} \mathrm{Co}$ (MW 509.3): C 28.27, H 5.10, N 10.99; found: C 28.35, H 4.93, N $10.80 \%$.
Physical measurements

The FT-IR spectroscopic measurements of the complex $\mathbf{1}$ have been taken on a 1760X Perkin Elmer Infrared spectrometer using $\mathrm{KBr}$ pellets. Chemical elemental analyses were performed by Quantitative Technologies, NJ, USA. The UV/visible spectra of 1 were recorded on a Hitachi model U2001 spectrophotometer in water and in the range from 300 to $900 \mathrm{~nm}$. Solid state and solution EPR measurements were taken in the temperature range $19-120 \mathrm{~K}$ and $17-25 \mathrm{~K}$, respectively, on a Bruker ER 200D-SRC X-band spectrometer, equipped with an Oxford ESR 9 cryostat, operating at $9.174 \mathrm{GHz}, 10 \mathrm{~dB}$. Magnetic susceptibility data were collected on powdered samples of $\mathbf{1}$ with a Quantum Design SQUID susceptometer in the 6-295 K temperature range under a $6.0 \mathrm{kG}$ applied magnetic field. Magnetization measurements were also performed at $5 \mathrm{~K}$ in the field range $0-5 \mathrm{~T}$.

Data collection and X-ray crystal structure determination

Crystallization from water/ethanol mixtures yielded pink prismatic crystals. A crystal with approximate dimensions $0.10 \times 0.20 \times 0.40 \mathrm{~mm}$ was mounted on a capillary. Diffraction measurements were taken on a Crystal Logic Dual Goniometer diffractometer using graphite monochromated Mo $\mathrm{K}_{\alpha}$ radiation. Details of crystal structure data collection are given in Table 1. Unit cell dimensions were determined and refined by using the angular settings of 25 automatically centered reflections in the range $11^{\circ}<2 \theta<23^{\circ}$. Intensity data were recorded using a $\theta-2 \theta$ scan to $2 \theta(\max )=50^{\circ}$ with a scan speed of $1.2^{\circ} / \mathrm{min}$ and scan range 2.5 plus $\alpha_{1} \alpha_{2}$ separation. Three standard reflections monitored every 97 reflections showed less than $3 \%$ variation and no decay. Lorentz, polarization, and psi-scan absorption corrections were applied using Crystal Logic software. The structure was solved by direct methods using SHELXS-86 [16] and refined by full-matrix least-squares techniques on $F^{2}$ with SHELXL-93 [17] using 1745 reflections and refining 194 parameters. The maximum and minimum residual peaks in the final difference map were 0.299 and $-0.346 \mathrm{e} / \mathrm{A}^{3}$. The largest shift/esd in the final cycle was 0.021 . All hydrogen atoms were located by difference maps and refined isotropically. All non-hydrogen atoms were refined anisotropically.

Table 1 Summary of crystal, intensity collection, and refinement data for $\left(\mathrm{NH}_{4}\right)_{4}\left[\mathrm{Co}\left(\mathrm{C}_{6} \mathrm{H}_{5} \mathrm{O}_{7}\right)_{2}\right](\mathbf{1})$

\begin{tabular}{ll}
\hline Empirical formula & $\mathrm{C}_{12} \mathrm{H}_{26} \mathrm{CoN}_{4} \mathrm{O}_{14}$ \\
\hline Formula weight & 509.30 \\
Temperature & $298 \mathrm{~K}$ \\
Wavelength & $\mathrm{Mo} \mathrm{K}_{\alpha}(0.71073 \AA)$ \\
Space group & $P 2_{1} / c$ \\
$a$ & $8.799(3) \AA$ \\
$b$ & $13.530(4) \AA$ \\
$c$ & $9.102(3) \AA$ \\
$\beta$ & $113.44(1)^{\circ}$ \\
$V, Z$ & $994.1(6) \AA^{3}, 2$ \\
$D_{\text {calcd }}$ & $1.701 \mathrm{Mg} \mathrm{m}^{-3}$ \\
Abs. coeff. ( $\mu)$ & $0.945 \mathrm{~mm}^{-1}$ \\
Reflections collected & 1865 \\
Independent reflections & $1746[R(\mathrm{int})=0.0121]$ \\
Data/restraints/parameters & $1745 / 0 / 194$ \\
Goodness-of-fit on $F^{2}$ & 1.107 \\
Observed reflections $[I>2 \sigma(I)]$ & 1465 \\
$R^{\mathrm{a}}$ & $R 1=0.0341, w R 2=0.0821$ \\
$R$ indices (all data) & $R 1=0.0450, w R 2=0.0886$ \\
\hline
\end{tabular}

${ }^{\text {a }} R 1$ based on $F$ values, $w R 2$ based on $F^{2}$ 


\section{Results}

Synthesis

Complex 1 was synthesized via a simple reaction between $\mathrm{Co}(\mathrm{II})$ and citrate with a 1:2 molar ratio in an aqueous solution at $\mathrm{pH} \sim 8$ (Eq. 1):

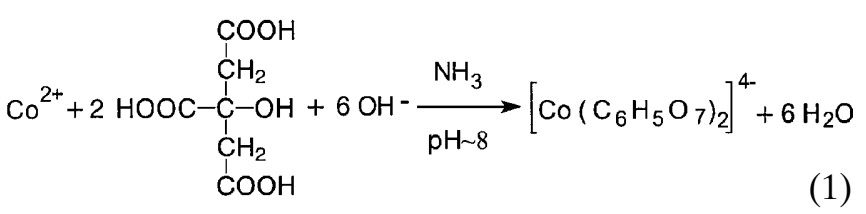

Catalytic in both the control of the $\mathrm{pH}$ as well as the neutralization of the resulting anionic charge of the emerging cobalt-citrate complex was the use of ammonia as a base. The $\mathrm{NH}_{4}{ }^{+}$ion acting as a counterion contributed substantively to the isolation of the reaction product. The synthetic procedure followed throughout the reaction led, upon ethanol precipitation, to a pink-colored crystalline material. That material was further used for spectroscopic and structural characterization purposes. Elemental analysis on the derived product suggested the formulation $\left(\mathrm{NH}_{4}\right)_{4}\left[\mathrm{Co}\left(\mathrm{C}_{6} \mathrm{H}_{5} \mathrm{O}_{7}\right)_{2}\right]$ (1). The crystals isolated from the reaction were stable in air for long periods of time. The product, complex $\mathbf{1}$, is soluble in aqueous solutions at $\mathrm{pH} \sim 7$.

\section{Crystal structure}

The X-ray structure of $\mathbf{1}$ consists of centrosymmetric anions of $\left[\mathrm{Co}\left(\mathrm{C}_{6} \mathrm{H}_{5} \mathrm{O}_{7}\right)_{2}\right]^{4-}$ and $\mathrm{NH}_{4}{ }^{+}$counterions. An ORTEP diagram of the anion $\left[\mathrm{Co}\left(\mathrm{C}_{6} \mathrm{H}_{5} \mathrm{O}_{7}\right)_{2}\right]^{4-}$ is shown in Fig. 1. Selected interatomic distances and angles are given in Table 2. The two citrates act as triply deprotonated ligands coordinated in a distorted octahedral geometry about the metal. Each citrate employs both of its central carbon anchors, the carboxylate and protonated hydroxyl moieties, to bind to

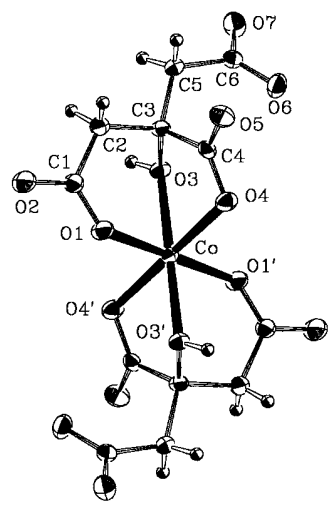

Fig. 1 Structure of the $\left[\mathrm{Co}\left(\mathrm{C}_{6} \mathrm{H}_{5} \mathrm{O}_{7}\right)_{2}\right]^{4-}$ anion with the atom labelling scheme in $\mathbf{1}$. Thermal ellipsoids are drawn by ORTEP and represent $50 \%$ probability surfaces
Table 2 Selected bond lengths $(\AA)$ and angles $\left(^{\circ}\right)$ for $\mathbf{1}$

\begin{tabular}{lc}
\hline $\mathrm{Co}-\mathrm{O}(1)$ & $2.051(2)$ \\
$\mathrm{Co}-\mathrm{O}(4)$ & $2.075(2)$ \\
$\mathrm{Co}-\mathrm{O}(3)$ & $2.157(2)$ \\
$\mathrm{O}(1)-\mathrm{C}(1)$ & $1.266(3)$ \\
$\mathrm{O}(3)-\mathrm{C}(3)$ & $1.443(3)$ \\
$\mathrm{O}(4)-\mathrm{C}(4)$ & $1.279(3)$ \\
$\mathrm{O}(1)-\mathrm{Co}-\mathrm{O}\left(1^{\prime}\right)^{\mathrm{a}}$ & 180.0 \\
$\mathrm{O}(1)-\mathrm{Co}-\mathrm{O}\left(4^{\prime}\right)$ & $91.37(8)$ \\
$\mathrm{O}(1)-\mathrm{Co}-\mathrm{O}(4)$ & $88.63(8)$ \\
$\mathrm{O}(1)-\mathrm{Co}-\mathrm{O}\left(3^{\prime}\right)$ & $94.21(7)$ \\
$\mathrm{O}(4)-\mathrm{Co}-\mathrm{O}\left(3^{\prime}\right)$ & $105.20(7)$ \\
$\mathrm{O}(1)-\mathrm{Co}-\mathrm{O}(3)$ & $85.79(7)$ \\
$\mathrm{O}(4)-\mathrm{Co}-\mathrm{O}(3)$ & $74.80(7)$ \\
\hline
\end{tabular}

a Symmetry transformations used to generate equivalent atoms: $-x+1,-y,-z$

the metal, thus exemplifying its ability to act as an effective metal ion chelator. The coordination requirements of the octahedron are fulfilled by employment of one of the terminal carboxylate groups of citrate, which binds to the metal ion in a monodentate fashion. The remaining terminal carboxylate does not participate in coordination, and dangles free, away from the complex. Since Co(II) finds itself in an octahedral field of oxygen atoms, the bonds formed with the latter earmark the geometric details of the emerging complex. The Co-O distances found in $\mathbf{1}$ [2.051(2)-2.157(2) $\AA$ ] are of comparable length with those found in $\left[\mathrm{Co}^{\mathrm{II}}\left\{\mathrm{Me}_{3} \mathrm{NCH}_{2} \mathrm{CO}_{2}\right\}_{2}\left(\mathrm{H}_{2} \mathrm{O}\right)_{4}\right] \mathrm{Cl}_{2} \cdot 4 \mathrm{H}_{2} \mathrm{O}$ [2.087(2)-2.101(2) $\AA$ ] [18], [Co ${ }^{\mathrm{II}}\left(\mathrm{EtOH}_{6}\right)_{6}\left[\mathrm{CoBr}_{4}\right]$ [2.01(3)2.14(3) $\AA$ ] [19], and [ $\left.\mathrm{Co}^{\mathrm{II}}\left\{\mathrm{CO}_{2} \mathrm{CH}_{2} \mathrm{CH}(\mathrm{OH}) \mathrm{CO}_{2}\right\}\right] \cdot 3 \mathrm{H}_{2} \mathrm{O}$ [2.067(3)-2.136(3) $\AA$ ] [20]. Two of the C-O distances in $1[2.157(2) \AA]$ are longer than the rest [2.051(2)2.075(2) A] , denoting a distortion in the octahedral coordination geometry around $\mathrm{Co}(\mathrm{II})$. The latter metal ion with a high-spin $\mathrm{d}^{7}$ electron configuration is subject to a Jahn-Teller effect in an octahedral field. As a result, a tetragonal distortion arises and is actually observed in the structure of the $\mathrm{Co}$ (II)-citrate complex. Complex $\mathbf{1}$ is isostructural with the $\mathrm{Cu}(\mathrm{II})$ [21], $\mathrm{Zn}(\mathrm{II})$ [22], and $\mathrm{Mn}(\mathrm{II})$ [23] congener complexes of citrate and very similar to $\left(\mathrm{NH}_{4}\right)_{4}\left[\mathrm{Ni}^{\mathrm{II}}\left(\mathrm{C}_{6} \mathrm{H}_{5} \mathrm{O}_{7}\right)_{2}\right]$. $2 \mathrm{H}_{2} \mathrm{O}$ [24]. The only mixed ligand $\mathrm{Co}(\mathrm{III})$-citrate complex known so far is $\left[\mathrm{Co}\left(\mathrm{C}_{6} \mathrm{H}_{5} \mathrm{O}_{7}\right)\left(\mathrm{C}_{6} \mathrm{H}_{18} \mathrm{~N}_{4}\right)\right] \cdot 5 \mathrm{H}_{2} \mathrm{O}$ [25], where the citrate is coordinated to the metal ion in the triply deprotonated state as a bidentate ligand.

The angles within the tetragonal plane range from $85.79(7)$ to $94.21(7)^{\circ}$, whereas those involving the apical oxygen atoms range from $74.80(7)$ to $105.20(7)^{\circ}$. The angle variability observed here appears to be similar to that seen in the case of other metal ion citrate complexes such as $\mathrm{Ni}(\mathrm{II})$ [24], $\mathrm{Cu}$ (II) [21], $\mathrm{Zn}$ (II) [22], and $\mathrm{Mn}(\mathrm{II})$ [23] analogs.

The carbon atoms $\mathrm{C}(1), \mathrm{C}(2), \mathrm{C}(3), \mathrm{C}(5)$, and $\mathrm{C}(6)$ of the citrate backbone are coplanar with the largest standard deviation $0.060 \AA$ for $\mathrm{C}(3)$. The $\mathrm{O}(3)$ $\mathrm{C}(3)-\mathrm{C}(4)$ plane of the central carboxylate group is rotated $\sim 12^{\circ}$ out of the $\mathrm{O}(4)-\mathrm{C}(4)-\mathrm{O}(5)$ plane. The 
terminal carboxylate planes $\mathrm{O}(1)-\mathrm{C}(1)-\mathrm{O}(2)$ and $\mathrm{O}(6)$ $\mathrm{C}(6)-\mathrm{O}(7)$ are rotated $\sim 3.3^{\circ}$ and $\sim 41^{\circ}$ respectively from the $\mathrm{C}(1), \mathrm{C}(2), \mathrm{C}(3), \mathrm{C}(5), \mathrm{C}(6)$ plane. The angle between the terminal carboxylate planes $\mathrm{O}(1)$ $\mathrm{C}(1)-\mathrm{O}(2)$ and $\mathrm{O}(6)-\mathrm{C}(6)-\mathrm{O}(7)$ is $\sim 41^{\circ}$. The torsion angle $\mathrm{H}-\mathrm{O}(3)-\mathrm{C}(3)-\mathrm{C}(4)$ for the hydrogen of the hydroxyl group is $171.5^{\circ}$. The above values are very similar to those observed for the manganese analog [23], but differ significantly from those reported for the zinc analog [22].

The protonated hydroxyl group is strongly hydrogen-bonded to the non-coordinated deprotonated carboxylate moiety of an adjacent complex anion, thus forming polymeric chains along the $c$ axis $\left[\mathrm{HO}(3) \cdots \mathrm{O}\left(7^{\prime}\right)=1.767 \AA, \mathrm{O}(3) \cdots \mathrm{O}\left(7^{\prime}\right)=2.638 \AA, \mathrm{O}(3)-\right.$ $\left.\mathrm{HO}(3) \cdots \mathrm{O}\left(7^{\prime}\right)=174.4^{\circ} ; \quad \mathrm{O}\left(7^{\prime}\right): 1-x,-y, 1-z\right]$. The hydrogen-bonding network is further extended by the involvement of the ammonium counterions and the complex's ligand carboxylates. It may very well be that formation of such an extensive hydrogen-bonding network leads to a stable lattice for complex $\mathbf{1}$.

\section{Electronic spectroscopy}

The UV/visible spectrum of $\mathbf{1}$ was taken in water at $\mathrm{pH} \sim 7$ in the range from 300 to $900 \mathrm{~nm}$. The spectrum shows a major peak at $\lambda_{\max }=508 \mathrm{~nm}(\varepsilon=13)$, a subtly distinguishable shoulder around $458 \mathrm{~nm}(\varepsilon \sim 8)$, and another weak band at $610 \mathrm{~nm}(\varepsilon=2)$. The observed absorption features for $\mathbf{1}$ are in consonance with those predicted and shown in the literature for a $\mathrm{Co}(\mathrm{II}) \mathrm{d}^{7}$ octahedral species [26].

\section{Infrared spectroscopy}

The FT infrared spectrum of $\mathbf{1}$ exhibits strong absorptions for the carbonyls of the citrate carboxylate ligands. Asymmetric stretching vibrations $v_{\mathrm{as}}\left(\mathrm{COO}^{-}\right)$ appear between 1615 and $1577 \mathrm{~cm}^{-1}$, whereas the symmetric ones $v_{\mathrm{s}}\left(\mathrm{COO}^{-}\right)$appear between 1429 and $1380 \mathrm{~cm}^{-1}$. All of the bands are shifted to lower frequencies compared to the free citric acid. The difference, $\Delta\left\{v_{\mathrm{as}}\left(\mathrm{COO}^{-}\right)-v_{\mathrm{s}}\left(\mathrm{COO}^{-}\right)\right\}[27,28]$, is around $200 \mathrm{~cm}^{-1}$, indicating the presence of deprotonated carboxylate groups free or coordinated to the metal in a monodentate fashion, in agreement with the observed features in the X-ray crystal structure of $\mathbf{1}$.

\section{Magnetic susceptibility measurements}

Variable-temperature, solid-state magnetic susceptibility data were collected on a powdered sample in a $6.0 \mathrm{kG}$ applied magnetic field and in the temperature range $6.0-295 \mathrm{~K}$. The $\chi_{\mathrm{M}} T$ versus $T$ data are shown in Fig. 2.

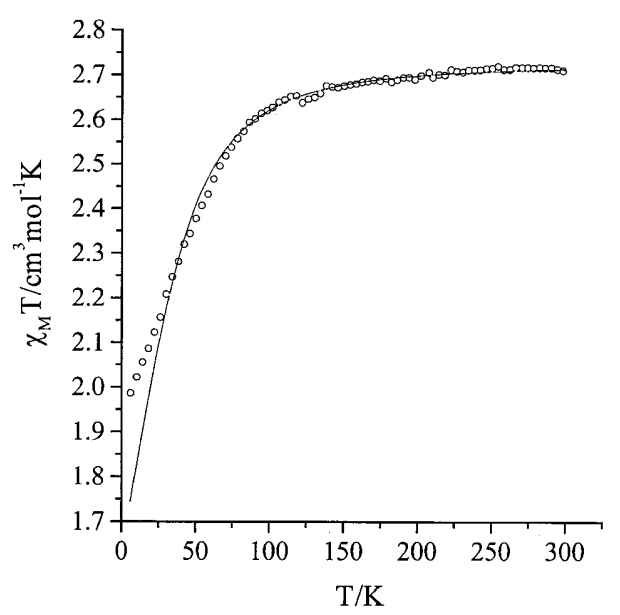

Fig. 2 Temperature dependence of the molar susceptibility of complex 1 in a field of $6000 \mathrm{G}$ (open circles). The solid line represents the fitting (see text)

The $\chi_{\mathrm{M}} T$ values decrease from $2.712 \mathrm{~cm}^{3} \cdot \mathrm{mol}^{-1} \mathrm{~K}$ at $295 \mathrm{~K}$ to $1.98 \mathrm{~cm}^{3} \cdot \mathrm{mol}^{-1} \mathrm{~K}$ at $6 \mathrm{~K}$. The high-temperature value of $\chi_{\mathrm{M}} T$ is higher than $1.875 \mathrm{~cm}^{3} \cdot \mathrm{mol}^{-1}$ $\mathrm{K}$, the value that would be expected for one $S=3 / 2$ spin. Nevertheless, it is consistent with the anisotropic nature of the metal ion where the orbital contribution is important. The decrease of $\chi_{\mathrm{M}} T$ with temperature is consistent with an extensive first-order spin-orbit coupling and resultant splitting between the Kramers' doublets in the orbitally degenerate ground state of high-spin $\mathrm{Co}(\mathrm{II})$ in octahedral coordination. The data are consistent with the presence of a spin $S=3 / 2$, isotropic $g=2.42$, and a very large zero-field splitting $D=0.83 \mathrm{~cm}^{-1}$. The data were analyzed in the hightemperature region (100-295 K) with the Curie-Weiss law and the fitting procedure gave the following values: (1) $C=2.75 \mathrm{~cm}^{3} \cdot \mathrm{mol}^{-1} \mathrm{~K}$, (2) $\theta=-4.44$, indicating a small antiferromagnetic interaction, possibly intermolecular in origin.

Furthermore, the magnetization measurements at $5 \mathrm{~K}$ and in the field range 0-5 $\mathrm{T}$ were fitted to a Brillouin function of a $S=3 / 2$ system with $g=2.0$ and are shown in Fig. 3. The non-coincidence of the two curves is in accordance with the orbital contribution.

\section{Electron paramagnetic resonance}

The EPR spectrum of complex $\mathbf{1}$ was taken in the range from 120 to $19 \mathrm{~K}$ for the solid state and from 25 to $17 \mathrm{~K}$ for the solution. In the solid state, the spectrum at $120 \mathrm{~K}$ exhibits a broad unresolved signal, which upon lowering the temperature deconvolutes into more distinct lines owing to the fast spin-lattice relaxation time of high-spin $\mathrm{Co}(\mathrm{II})$. Below the temperature of $62 \mathrm{~K}$, there is a clear manifestation of the signal belonging to the complex, with a final form being achieved at $19 \mathrm{~K}$ (Fig. 4). The behavior of complex $\mathbf{1}$ 


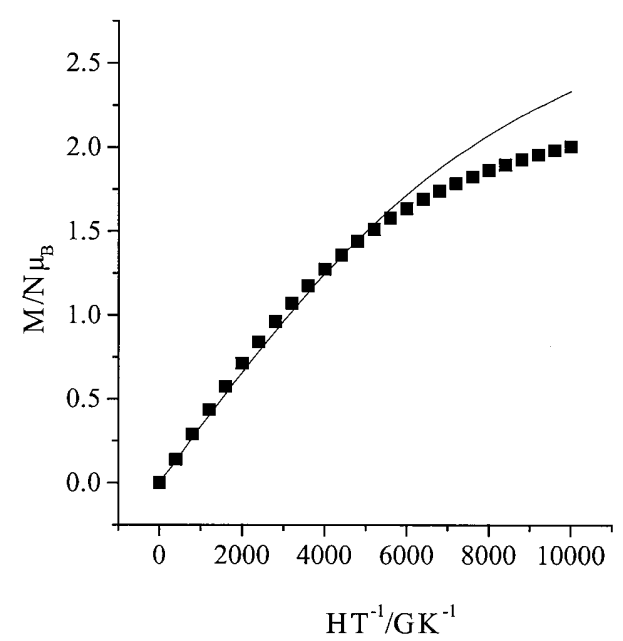

Fig. 3 Field dependence of the reduced magnetization, in the form $\mathrm{M} / \mathrm{N} \mu_{\mathrm{B}}$, at $5 \mathrm{~K}$ for complex $\mathbf{1}$. The solid line represents the Brillouin function for a system $\mathrm{S}=3 / 2$ with $g=2$

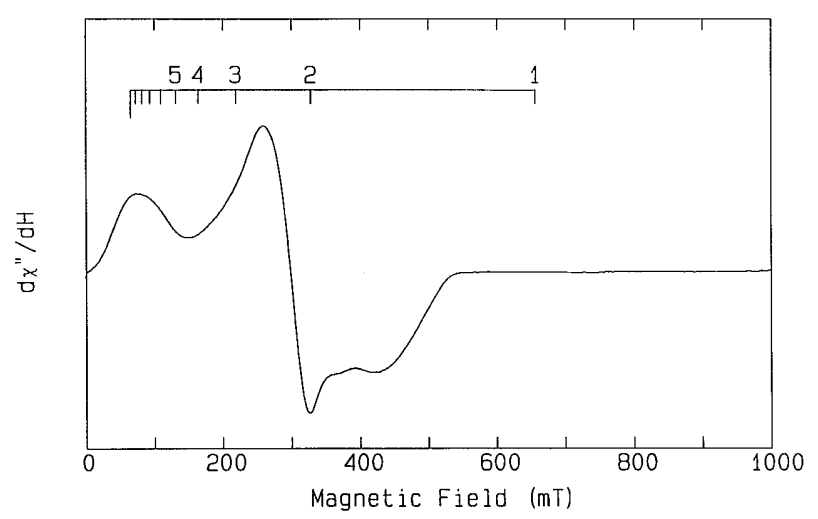

Fig. 4 EPR spectrum of $\mathbf{1}$ in the solid state at $19 \mathrm{~K}$

in the EPR reflects clearly the presence of a high-spin $S=3 / 2 \mathrm{Co}$ (II) system with typical rhombic $g$-values at $g_{1}=8.32, g_{2}=2.18$, and $g_{3}=1.45$. The rhombicity value, $g_{1}-g_{2}=6.14$, is fairly large and reflects a significant asymmetry in the equatorial plane of Co(II) [29]. These $g$-values are in the range of those observed in similar high-spin octahedral $\mathrm{Co}(\mathrm{II})$ complexes, such as trans- $\left[\mathrm{Co}^{\mathrm{II}}(\text { malonamato })_{2}\left(\mathrm{H}_{2} \mathrm{O}\right)_{2}\right]$ [30]. Characteristic of the EPR signal of $\mathbf{1}$ is the presence of a broad feature slightly over $200 \mathrm{mT}$, which grows as the temperature of the spectrum decreases, resolves below $35 \mathrm{~K}$, and reaches maximum intensity at $19 \mathrm{~K}$. The line shapes are mostly dominated by the unresolved hyperfine interactions and by a distribution of $E / D$, where $D$ and $E$ describe the axial and rhombic zero-field splitting (ZFS) constants, respectively. The spread of $E / D$ results in a spread of $g$-values ( $g$-strain) [31]. The dominant broadening effect is realised when the $g$-strain is converted into $<B$-strain $>$ with the relation $\Delta B=-(h v / \beta)\left(\Delta g / g^{2}\right)$, where the parameters have their usual definitions. Thus, the largest and smallest $g$-values of the $S=3 / 2$ spectrum have field widths that differ by an order of magnitude, rationalizing why the high-field features of the spectra are so broad. The solution spectrum (with an integrated EPR concentration of $\sim 3.7 \mathrm{mM}$ ) of $\mathbf{1}$ at $4 \mathrm{~K}$ and at $\mathrm{pH} \sim 7$ confirmed the presence of a high-spin $\mathrm{Co}$ (II) ion in the presence of coordinated citrate ligands. The spectrum consists of two main features with $g$-values of $g_{\|}=6, g_{\perp}=1.75$. It seems, therefore, that in solution the environment of the $\mathrm{Co}(\mathrm{II})$ changes to a less distorted octahedral one.

\section{Discussion}

The presence of citric acid in biological fluids, such as human plasma, at relatively high concentrations (ca. $0.1 \mathrm{mM}$ ) [32], exemplifies its potential role as a predominant metal ion chelator. As in the case of other metals, including iron, chromium, copper, and zinc, citric acid coordinates to the trace metal ion cobalt under the reaction conditions employed in the present work. Cobalt, albeit encountered in minute quantities in the human body $(0.7 \mathrm{mg}$ for an average person of $70 \mathrm{~kg}$ ) [9], exhibits remarkable chemical and biochemical versatility, manifested in biological molecules such as vitamin $\mathrm{B}_{12}$ and coenzymes $\mathrm{B}_{12}$. Therefore, in light of that (bio)chemical significance of cobalt, the herein reported complex $\mathbf{1}$ provides the first example of cobalt(II)-citrate species with the following properties: (1) it is a mononuclear, low molecular weight complex; (2) it contains a physiologically relevant ligand bound to the metal; (3) it is a soluble form of cobalt; and (4) it retains the electronic and magnetic properties of the metal ion $\mathrm{Co}(\mathrm{II})$. The aforementioned attributes may be crucial for a cobalt-citrate species such as $\mathbf{1}$ to function avidly in a biodistribution scheme of potential physiological relevance. Furthermore, the ability of citrate to promote metal ion solubilization and thus contribute to mobilization toward diverse biological tissues may very well be reflected in 1. The basic physical and chemical characteristics of $\mathbf{1}$ indicate a reasonable complex form of cobalt potentially bioavailable and poised to influence that metal's aqueous biological chemistry in key biosynthetic processes, such as the corrinoid biosynthesis of $\mathrm{B}_{12}$ or other pathway(s) leading to toxic cellular manifestations [33-35] and pathophysiological symptoms [36, 37].

In fact, complex 1 represents but one example among the multitude of candidates that could be present in aqueous solutions. Such candidates had been probed in a number of solution studies targeting cobalt tricarboxylic acid complexes. Among the complex forms investigated and predicted to exist in the cobalt(II)-citrate system as stable species were $\mathrm{Co}\left(\mathrm{C}_{6} \mathrm{H}_{5} \mathrm{O}_{7}\right)^{-}, \mathrm{Co}\left(\mathrm{C}_{6} \mathrm{H}_{6} \mathrm{O}_{7}\right)$, etc. [36, 37]. It is, thus, very likely that, under variable experimental conditions, several $\mathrm{Co}$ (II)-citrate complexes purported to 
exist in equilibria (not excluding the aforementioned) could be isolated and characterized. Meticulous endeavors aiming at the synthesis, isolation, and characterization of such elusive low molecular weight cobalt-citrate complexes of biological significance are currently in progress in our laboratories.

Acknowledgements This work was supported with funds provided by the Department of Chemistry, University of Crete, Greece. The financial assistance to C.P.R. and A.T. by the Agricultural Bank of Greece (A.T.E.) and Mr. John Boutaris is gratefully acknowledged.

\section{References}

1. Srere PA (1972) Curr Top Cell Regul 5:229-283

2. Glusker JP (1980) Acc Chem Res 13:345-352

3. Krebs HA, Johnson WA (1937) Enzymologia 4:148-156

4. Crans DC (1995) In: Sigel H, Sigel A (eds) Metal ions in biological systems, vol 31. Dekker, New York, pp 147-209

5. Beinert H (1990) FASEB J 4:2483-2491

6. Beinert H, Kennedy MC (1989) Eur J Biochem 186:5-15

7. Lippard SJ, Berg JM (1994) In: Principles of bioinorganic chemistry. University Science Books, Mill Valley, Calif., pp 352-354

8. Liang J, Madden M, Shah VK, Burris RH (1990) Biochemistry 29:8577-8581

9. Taylor DM, Williams DR (1995) Trace element medicine and chelation therapy. Royal Society of Chemistry, Cambridge

10. Balachandran S, Vishwakarma RA, Monaghan SM, Prelle A, Stamford NPJ, Leeper FJ, Battersby AR (1994) J Chem Soc Perkin Trans $1487-491$

11. Battersby AR (1993) Acc Chem Res 26:15-21

12. Debussche L, Couder M, Thibaut D, Cameron B, Crouzet J, Blanche F (1992) J Bacteriol 22:7445-7451

13. Hamilton EMN, Gropper SAS (1987) The biochemistry of human nutrition. West, New York, pp 298-301

14. Helis HM, de Meester P, Hodgson DJ (1976) J Am Chem Soc 99:3309-3312
15. Waldbott GL (1973) Health effects of environmental pollutants. Mosby, St. Louis

16. Sheldrick GM (1986) SHELXS-86: structure solving program. University of Göttingen, Germany

17. Sheldrick GM (1993) SHELXL-93: crystal structure refinement. University of Göttingen, Germany

18. Chen X-M, Mak TCW (1992) Acta Crystallogr C48:1211-1214

19. Bkouche-Waksman I, L'Haridon P (1979) Bull Soc Chim Fr $1-2$ : I50-I53

20. Kryger L, Rasmussen SE (1972) Acta Chem Scand 26:2349-2359

21. Bott RC, Sagatys DS, Lynch DE, Smith G, Kennard CHL, Mak TCW (1991) Aust J Chem 44:1495-1498

22. Swanson R, Ilsley WH, Stanislowski AG (1983) J Inorg Biochem 18:187-194

23. Matzapetakis M, Karligiano N, Bino A, Dakanali M, Raptopoulou CP, Tangoulis V, Terzis A, Giapintzakis J, Salifoglou A (2000) Inorg Chem accepted for publication

24. Zhou Z-H, Lin Y-J, Zhang H-B, Lin G-D, Tsai K-R (1997) J Coord Chem 42:131-141

25. Job R, Kelleher PJ, Stallings WC Jr, Monti CT, Glusker JP (1982) Inorg Chem 21:3760-3764

26. Drago RS (1977) Physical methods in chemistry. Saunders, Philadelphia, pp 359-410

27. Djordjevic C, Lee M, Sinn E (1989) Inorg Chem 28:719-723

28. Deacon GB, Philips R (1980) Coord Chem Rev 33:227-250

29. Zarembowitz J, Kahn O (1984) Inorg Chem 23:589-593

30. Vansant C, Desseyn HO, Tangoulis V, Raptopoulou CP, Terzis A, Perlepes SP (1995) Polyhedron 14:2115-2125

31. Hagen WR, Hearshen DO, Sands RH, Dunham WR (1985) J Magn Reson 61:220-232

32. Martin RB (1986) J Inorg Biochem 28:181-187

33. Moorhouse CP, Halliwell B, Grootveld M, Gutteridge JMC (1985) Biochim Biophys Acta 843:261-268

34. Robison SH, Cantoni O, Costa M (1982) Carcinogenesis $3: 657-662$

35. Kusaka Y, Jokohama K, Sera Y, Yamamoto S, Sone S, Kyono H, Shirakawa T, Goto S (1986) Br J Ind Med 43:474-485

36. Campi E, Ostacoli G, Meirone M, Saini G (1964) J Inorg Nucl Chem 26:553-564

37. Li NC, Lindenbaum A, White JM (1959) J Inorg Nucl Chem 12:122-128 